\title{
OFERTA DE ACESSIBILIDADE NA PREFEITURA E CÂMARA DEVEREADORES DO MUNICÍPIO DE SANTA ROSA/RS
}

\author{
Monize Sâmara Visentini* \\ Abel Eduardo Auth** \\ Ari Söthe***
}

\begin{abstract}
Resumo
Tendo em vista a importância da acessibilidade urbana na promoção da qualidade de vida e legitimação do exercício da cidadania às pessoas com deficiência, neste trabalho ${ }^{1}$ analisa-se a sua oferta, no ano de 2017, na Prefeitura e na Câmara de Vereadores do Município de Santa Rosa/RS. O estudo de abordagem qualitativa foi realizado por meio de análise documental, entrevistas, e observação direta. A análise documental abrangeu normas federais e legislação municipal. Por meio das entrevistas, verificou-se a percepção de 12 gestores públicos municipais. Também se realizou uma observação estruturada dos critérios de acessibilidade. Os resultados apontam que o município se mostrou um dos precursores no que se refere à legislação que atende às pessoas com deficiência. Na percepção dos gestores, a estrutura da Câmara mostrou-se mais acessível do que o prédio da Prefeitura Municipal. Conclusivamente, percebe-se que a presença de pessoas com deficiência é pouco significativa nos espaços públicos municipais investigados, impedindo vivências concretas e consciências das limitações desses munícipes ao frequentá-los.
\end{abstract}

Palavras-chave: Gestores Municipais. Pessoas com Deficiência. Entrevistas.

\footnotetext{
* Doutora em Administração, pela Universidade Federal do Rio Grande do Sul (UFRGS), mestre em Administração, pela Universidade Federal de Santa Maria (UFSM), administradora, pela UFSM. Professora do quadro permanente do Programa de Pós-Graduação em Desenvolvimento e Políticas Públicas da Universidade Federal da Fronteira Sul (UFFS-Cerro Largo).

E-mail: monize.visentini@uffs.edu.br

** Mestre em Desenvolvimento e Políticas Públicas pela UFFS-Cerro Largo, Engenheiro Civil (URI- Santo Angelo).

E-mail: abelauth@hotmail.com

*** Doutor em Desenvolvimento Regional, pela Universidade Regional de Blumenau (FURB). Mestre em Ciências Contábeis, contador, pela Universidade São Francisco (USF). Professor da UFFS-Cerro Largo.

E-mail: ari.sothe@uffs.edu.br

1 Este trabalho é resultante da dissertação de mestrado do segundo autor deste artigo, orientado pela primeira autora.
} 


\section{Introdução}

A acessibilidade é uma questão central para promover a qualidade de vida e legitimar o exercício da cidadania de pessoas com deficiência ${ }^{2}$, assim como, é uma importante ferramenta de acesso dessa população à educação, saúde e ao trabalho (LIMA, 2006). Assim, compõe o conceito de cidadania, no qual os indivíduos têm direitos assegurados por lei que devem ser respeitados (LAMÔNICA; ARAÚJO FILHO; SIMOMELLI, 2008). O percentual da população mundial que possui algum tipo de deficiência é de 10\% (ONU, 2016) e, no Brasil, esse percentual chega a 6,2\% (IBGE, 2013).

No país, a legislação é bem estruturada, porém a sua implantação não é satisfatória, exigindo novos projetos de revitalização e planejamento urbano (CRUZ, 2011). A acessibilidade disponível para as pessoas com deficiência deixou de ser facultativa e tornou-se previsão legal, explícita na legislação. Nesse sentido, o plano de Mobilidade Urbana desenvolvido pelo Ministério das Cidades (SEMOB, 2015) em parceria com a Secretaria Nacional de Transporte e Mobilidade Urbana tem por objetivo dotar as cidades de infraestrutura e transporte coletivo urbano eficaz. O plano atenta para a importância da oferta da acessibilidade e da sustentabilidade na construção da história de um país, principalmente, no quesito infraestrutura.

A busca pela acessibilidade prevista em lei só é possível por meio de políticas públicas eficazes, as quais devem ser elaboradas com base no diagnóstico de órgãos públicos como prefeituras e câmaras de vereadores. Diante disto, buscou-se neste estudo analisar o cenário da oferta de acessibilidade, no ano de 2017, na Prefeitura e na Câmara de Vereadores do município de Santa Rosa/RS, a partir da percepção dos seus gestores públicos municipais.

O estudo se justifica a partir da precariedade da oferta de acessibilidade nos órgãos públicos municipais, sendo que 42,6\% dos municípios brasileiros não possui nenhum item acessível (IBGE, 2011). Além da carência na estrutura física, é evidente a falha na estrutura administrativa, responsável por manejar a oferta da acessibilidade, que recebe pouco investimento e, geralmente, não o emprega de modo eficiente (TAVARES FILHO et al., 2002).

$\mathrm{Na}$ direção contrária a esse cenário reproduzido nacionalmente, o Município de Santa Rosa/RS se mostrou pioneiro em referenciar as normativas técnicas de acessibilidade em suas exigências legais, como o Código de Obras Municipal e Plano Diretor Municipal. Assim, definiramse como objetos de estudo a Prefeitura e Câmara de Vereadores de Santa Rosa/RS pelo seu destaque na iniciativa de medidas de implantação de acessibilidade em relação aos outros municípios pertencentes ao Conselho Regional de Desenvolvimento (COREDE) Fronteira Noroeste. Os
2 No Brasil, tornou-se bastante popular, acentuadamente entre 1986 e 1996, o uso do termo portador de deficiência (e suas flexões no feminino e no plural). Pessoas com deficiência vêm ponderando que elas não portam deficiência; que a deficiência que elas têm não é como coisas que às vezes portamos e às vezes não portamos (por exemplo, um documento de identidade, um guarda-chuva). O termo preferido passou a ser pessoa com deficiência (SASSAKI, 2002, p. 7). 
resultados advindos do presente trabalho poderão ser utilizados na elaboração de novas políticas públicas de promoção de acessibilidade não apenas no respectivo município, mas em todos os municípios integrantes do COREDE Fronteira Noroeste, principalmente, na reestruturação dos seus Planos Diretores, buscando alinhar as diretrizes urbanas de desenvolvimento com a oferta da acessibilidade adequada à população.

\section{Fundamentação Teórica}

\section{Acessibilidade, Normas e Legislação}

Ao pensar em acessibilidade, remete-se esse termo às pessoas com deficiência, o que desencadeia um sentimento de compaixão, inferiorização e seu descrédito na participação ativa na comunidade. No entanto, Sassaki (2009, p. 2) ressalta que, "[...] a acessibilidade é uma qualidade, uma facilidade que desejamos ver e ter em todos os contextos e aspectos da atividade humana". Complementa, que a acessibilidade deve ser projetada sob os princípios do desenho universal para beneficiar qualquer pessoa, com ou sem deficiência (SASSAKI, 2009).

No Rio Grande do Sul, 15,01\% da população possui algum tipo de deficiência (IBGE, 2013), o que resulta num total aproximado de 1,5 milhões de habitantes. As barreiras arquitetônicas e sociais são obstáculos que impedem a inserção das pessoas com deficiência à sociedade, as quais devem ser combatidas. Nesse sentido, a promoção da acessibilidade tem como objetivo eliminar tais barreiras desenvolvendo a cidadania igualitária entre cidadãos comuns e pessoas com deficiência (BOLONHINI JUNIOR, 2010).

A implantação da acessibilidade às pessoas com deficiência se torna um problema de grande extensão territorial, pois, grande parcela da legislação sobre o tema não se concretiza no Brasil (CLEMENTE; CELESTINI, 2003). Desse modo, as pessoas com deficiência não carecem de medidas preferenciais, mas, sim, da eliminação das barreiras que impedem seu ingresso no mundo do trabalho, sendo que as mais cruciais são as de ordem social, principalmente, no que tange ao preconceito profissional.

Acessibilidade, de acordo com a ABNT NBR 9050/2015, é a possibilidade de condição e alcance com segurança de espaços, mobiliários, equipamentos urbanos, edificações, transporte, informação, comunicação e outros serviços abertos ao público, de uso coletivo, tanto em zona urbana como rural. A norma reuniu diversos fatores para criar as diretrizes normativas necessárias à promoção das medidas de acessibilidade:

No estabelecimento desses critérios e parâmetros técnicos foram consideradas diversas condições de mobilidade e de percepção do ambiente, com ou sem a ajuda de aparelhos específicos, como próteses, aparelhos de apoio, cadeiras de rodas, bengalas de 
rastreamento, sistemas assistivos de audição ou qualquer outro que venha a complementar necessidades individuais. (ABNT, 2015).

A sinalização dos serviços prestados pelos órgãos aos usuários deve se dar na recepção dos seus respectivos ambientes (ABNT, 2008), além da descrição clara e objetiva deve estar presente sobre forma de Libras tátil. "As instituições públicas e empresas prestadoras ou concessionárias de serviços públicos devem divulgar amplamente os locais, dias e horários do serviço de informação, para orientação e instrução adequadas, especialmente, destinados ao cidadão usuário de LIBRAS.” (ABNT, 2008, p. 4).

As vagas e espaços confinados, destinados a cadeirantes em teatros, anfiteatros e assemelhados devem atender as dimensões mínimas de 1,5 metros na horizontal e 80 centímetros na vertical (ABNT, 2015). $\mathrm{O}$ mobiliário de atendimento a cadeirantes, bem como interruptores ou pontos de acionamento, deve levar em conta o alcance manual máximo lateral e frontal para o seu o deslocamento (ABNT, 2015).

"Os elementos de acionamento para abertura de portas devem possuir formato de fácil pega, não exigindo firmeza, precisão ou torção do pulso para seu acionamento.” (ABNT, 2015, p. 4). As maçanetas das portas devem ser do tipo alavanca, com pelo menos 10 centímetros de comprimento e sem arestas vivas, assim como, devem estar afastadas a pelo menos 4 milímetros da superfície mais próxima e posicionadas a uma altura entre 80 a 110 centímetros do piso acabado (ABNT, 2015).

Os assentos para pessoas obesas também estão previstos (ABNT, 2015), os quais deverão ter profundidade variando entre 47 e 51 centímetros, largura do assento mínima de 75 centímetros e medida entre as bordas laterais no terço mais próximo do encosto.

A relevância social da norma ABNT NBR 9050 é tão grande para a elaboração de políticas públicas de acessibilidade que foi criado um Termo de Ajustamento de Conduta pelo Ministério Público Federal que reconhece a necessidade de sua publicidade gratuita, via internet, dentre outras normas de interesse social (LIMA, 2006). Logo, a norma encontrase disponível para amplo e irrestrito acesso a qualquer cidadão ou órgão público que manifeste interesse.

\section{Procedimentos Metodológicos}

A metodologia de caráter exploratória é atendida a partir de uma pesquisa qualitativa, ao compreender a percepção dos gestores públicos municipais entrevistados. A realização deste estudo teve por base a aplicação de dois instrumentos de coleta dos dados, elaborados com base no documento desenvolvido e validado pelo TCU (2012): roteiro de entrevista semiestruturado e roteiro de observação estruturada. 
As entrevistas foram realizadas no ano de 2017, com todos os 12 gestores (G1 a G12) das secretarias e órgãos de gestão do Município de Santa Rosa/RS, a fim de mensurar a sua percepção acerca da oferta de acessibilidade. Já a observação estrutura foi realizada in loco, na Prefeitura e na Câmara de Vereadores do município, para comparar o que estabelece a legislação, as respostas dos gestores e o real cenário de oferta da acessibilidade. Adicionalmente a essas técnicas de coleta de dados, realizou-se a análise documental das principais legislações municipais de Santa Rosa/RS (as Leis Complementares n. 33, de 11 de outubro de 2006, n. 58, de 12 de abril de 2010 e n. 118 de 28 de agosto de 2017), das normas técnicas vigentes (a ABNT NBR 9050/2015 e a ABNT NBR 15559/2008), bem como do relatório de pesquisa do TCU (2012), em sua auditoria em busca da acessibilidade.

Para a análise dos dados qualitativos, provenientes das entrevistas, aplicou-se a análise de conteúdo (BARDIN, 2006). Assim, buscando responder o objetivo geral do estudo, foram criadas um conjunto de categorias com base nos dados coletados e nas informações extraídas do roteiro de entrevista. Os resultados de cada uma das categorias foram analisados e discutidos individualmente a partir do referencial teórico abordado.

\section{Estrutura Física para Acessibilidade}

As cinco primeiras categorias identificadas a partir da realização das entrevistas relacionam-se com a estrutura física da Prefeitura e na Câmara de Vereadores do município.

A primeira categoria, circulação, que integra a estrutura física está baseada nas subcategorias acesso externo e deslocamento interno. A subcategoria acesso externo é a circulação acessível desde a via pública até a entrada do estabelecimento, constituída de espaços desprovidos de obstáculos que possam ser destinados a todas as pessoas com deficiência (ABNT, 2015). O acesso externo até a Prefeitura Municipal e a Câmara de Vereadores foi visto de forma positiva em se tratando de acessibilidade pelos gestores: "O deslocamento da via pública até a Prefeitura Municipal e até a Câmara de Vereadores está dentro dos padrões de acessibilidade, atendendo as pessoas com deficiência com rampas, por exemplo." (G3).

A subcategoria deslocamento interno foi citada pelos gestores como acessível somente na Câmara de Vereadores. "O deslocamento interno é mais complicado na Prefeitura Municipal do que na Câmara de Vereadores, pois além do segundo piso inacessível também não foram executadas ainda as reformas necessárias no prédio da Prefeitura Municipal.”(G11).

$\mathrm{Na}$ análise da segunda categoria, dispositivos de acesso a desníveis verticais, foram identificadas nas três subcategorias: rampas, escadas e elevadores. A primeira delas, rampas, é apontada como um dos dispositivos 
físicos mais importantes para promover acessibilidade (TAVARES FILHO et al.,2002). Quando questionados os gestores sobre as rampas na Prefeitura Municipal e na Câmara de Vereadores, foi observado que as rampas estão acessíveis na percepção dos mesmos, "[...] os cadeirantes conseguem ter acesso à Prefeitura Municipal e a Câmara de Vereadores pelas rampas, que dão condições para ingresso aos prédios, os problemas de acessibilidade maiores são internos, mas percebo que a parte de acesso até o interior dos prédios está tranquila.” (G7). A legislação municipal também prevê o uso de rampas e escadarias acessíveis em desníveis verticais: "[...] ser provida de escadarias e rampas acessíveis de acordo com as normas de acessibilidade." (SANTA ROSA, 2017, p. 62).

Outra subcategoria refere-se às escadas. $\mathrm{O}$ dimensionamento dos degraus e altura de corrimãos está dentro dos padrões de acessibilidade pela compreensão dos gestores na Prefeitura Municipal e na Câmara de Vereadores, porém os elementos construtivos do piso das escadas são, em sua maioria, escolhidos com finalidade estética, não antiderrapante e fotoluminescente como previsto nas normas de acessibilidade, "[...] as escadas em geral não possuem pisos com sinalização e antiderrapantes para que as pessoas com deficiência estejam amparados e possam circular de forma segura." (G10).

No que se refere à subcategoria elevadores, percebeu-se que muitos gestores públicos municipais abordaram a importância de sua utilização em função da sua necessidade onde é inviável tecnicamente a instalação de rampas, como de um pavimento ao outro. "Na Câmara já tem uma estrutura adequada, pois, lá tem uma rampa lateral e tem elevador, elemento muito importante, sendo que estes dois elementos me parecem ter suprido as demandas mais urgentes no que diz respeito à acessibilidade.” (G1). Na perspectiva dos gestores públicos, as rampas estão de acordo com os padrões de acessibilidade, e o elevador instalado na Câmara de Vereadores também, porém é necessário instalá-lo na Prefeitura Municipal para dar acesso ao segundo pavimento bem como realizar adaptações nas escadas, tanto da Prefeitura Municipal quanto da Câmara de Vereadores.

$\mathrm{Na}$ análise da categoria sinalização, foram identificadas duas subcategorias: piso tátil e linguagem braile. A primeira delas, piso tátil, é apontada como uma ferramenta de sinalização tátil necessária junto à recepção de todos os órgãos que atendam usuários externos (ABNT, 2008), a Prefeitura Municipal está trabalhando em um projeto para adequação de piso tátil:

$\mathrm{Na}$ Prefeitura Municipal está sendo trabalhado um projeto para [...] sinalização de todas as áreas, justamente para proporcionar o piso tátil, e assim a acessibilidade para os deficientes visuais. $\mathrm{Na}$ Câmara 
de Vereadores já existe em alguns pontos o piso tátil, sendo atendido parcialmente esse requisito de acesso para os deficientes visuais. (G6).

A segunda subcategoria é a linguagem braile, a qual está associada com mapas de instrução e orientação em braile. A implantação da sinalização em braile é inexistente tanto na Prefeitura Municipal quanto na Câmara de Vereadores na percepção da maioria dos entrevistados. No entanto, ainda muitos entendem que a Câmara de Vereadores está adiante nesse quesito. Percebe-se que não há orientação atualmente para pessoas com deficiências visuais: "A percepção de orientação dentro da Prefeitura Municipal e da Câmara de Vereadores para o deficiente visual é inexistente atualmente, pois, não há placas em braile que informem as salas ou até mesmo como chegar até os banheiros.”(G11). A sinalização tátil e de linguagem braile é inexistente na Prefeitura Municipal e na Câmara de Vereadores, ou seja, há muito a melhorar na percepção dos gestores públicos municipais.

A categoria mobiliário está baseada nas subcategorias mesas para cadeirante e assentos para obesos. A primeira delas: mesas para cadeirantes disponíveis para atendimentos aos usuários, deve oferecer fácil manuseio às pessoas com deficiência e dimensões e acessórios que facilitem o seu uso (PASTORE, 2000). Na Prefeitura Municipal e na Câmara de Vereadores os mobiliários não são adequados para permitir o encaixe de uma cadeira de rodas, com altura e afastamento horizontal necessário. Os gestores afirmam que as mesas possuem altura adaptada, no entanto, o problema é o seu encaixe inferior: “[...] o cadeirante não consegue entrar com as pernas por baixo das mesas porque a maioria possui obstáculos, sendo que para assinar documentos precisa ficar de lado ou afastado da mesa, ou então, pedir auxílio através de pranchetas." (G6).

A segunda subcategoria foi sobre os assentos para os obesos, quando questionados os gestores sobre esse item na Prefeitura Municipal e na Câmara de Vereadores identificou-se que eles não estavam previstos em nenhuma das duas benfeitorias. "Não há assentos reservados para pessoas com obesidade, com maior largura e maior resistência a peso, até porque não se teve reclamação até hoje sobre isso.” (G5). Além da adaptação das mesas necessária, os assentos para obesos também deverão ser adaptados e poderão, em um primeiro momento, ser disponibilizados nas áreas onde possuem maior fluxo de pessoas.

A categoria sanitários está baseada nas subcategorias dimensões mínimas, portas com largura adequada e barras de apoio. A ausência de banheiros acessíveis é apontada como um dos maiores problemas no ambiente de trabalho em se tratando de acessibilidade (CLEMENTE; CELESTINI, 2003), o que corrobora com a visão preconceituosa que colegas e chefes têm nos ambientes organizacionais, frente à incapacidade 
das pessoas com deficiência de exercerem sozinhos o mínimo correspondente às suas necessidades sanitárias básicas.

A primeira das subcategorias dimensões mínimas dos banheiros foi apontada como inadequada na Prefeitura Municipal por alguns gestores, “[...] os banheiros são muito apertados na maioria dos lugares, antigamente o prédio da Prefeitura Municipal era um galpão e foi feito tudo no estilo vestiários, até é apertado para pessoas com deficiência.” (G9).

De outro modo, na Câmara de Vereadores os entrevistados afirmaram que existe a presença de sanitários acessíveis com as dimensões mínimas adequadas para fazer o acesso e o giro com uma cadeira de rodas: "[...] a Câmara de Vereadores passou por reformas que adequaram todos os seus banheiros, onde o cadeirante consegue acessar de forma independente e fazer suas necessidades fazendo as devidas manobras com a cadeira de rodas." (G3).

Quando questionados sobre a subcategoria portas com largura adequada, percebeu-se que no prédio da Prefeitura Municipal elas são estreitas e pequenas para os banheiros em alguns lugares e em tamanhos acessíveis em outros: "[...] na Prefeitura alguns banheiros possuem portas muito estreitas e que quase encostam no vaso sanitário ao serem abertas, já outros que são a minoria, possuem portas mais largas que acredito dar passagem a um cadeirante." (G2).

A terceira subcategoria se refere às barras de apoio próximas às bacias sanitárias, as quais são responsáveis pela transição segura do cadeirante para o vaso sanitário. Os gestores afirmaram que na Prefeitura Municipal as barras de apoio até existem, porém são inadequadas: “[...] as barras de apoio são muito altas nos banheiros da Prefeitura, ou então não existem, são poucas barras instaladas e ainda estão de forma equivocada.” (G2).

A Prefeitura Municipal também não possui pelo menos um banheiro acessível na percepção da maioria dos gestores, e já a Câmara de Vereadores possui mais de um banheiro adaptado, porém, a maioria dos gestores afirmou que a Prefeitura Municipal está tomando medidas para alterar esse cenário e viabilizando projetos de reforma.

\section{Estrutura de Serviços e Recursos para Acessibilidade}

Outro grupo identificado refere-se à estrutura de serviços e recursos da Prefeitura e na Câmara de Vereadores do município. A categoria serviços está baseada nas subcategorias intérprete de libras, divulgação e propagandas e painéis e monitores. $\mathrm{Na}$ Prefeitura Municipal, existe um profissional habilitado em libras com formação, o qual tem função de recepcionista:

Nossa recepcionista fala em libras, e ainda se ver por outros olhos na educação e na saúde também temos pessoas qualificadas em 
áreas que podem apoiar progressivamente e em conjunto, temos que ir ampliando nosso município mesmo, apoiar financeiramente a APADA que é a instituição que educa deficientes auditivos e buscar parcerias com estas instituições. (G1).

$\mathrm{Na}$ Câmara de Vereadores alguns gestores afirmaram desconhecimento sobre profissional habilitado em libras, outros já afirmaram que existiria a presença desse profissional, e ainda outros afirmaram que a secretária que trabalhava no prédio da Prefeitura Municipal era itinerante: “[...] a nossa intérprete de libras atua em vários locais quando é preciso, nas seções da Câmara de Vereadores, por exemplo, ou então, nas escolas quando é solicitado, porém ela atua de forma efetiva em nosso prédio da Prefeitura." (G5).

Quando questionados os gestores sobre a subcategoria divulgação e propaganda muitos afirmaram que a divulgação de materiais audiovisuais, tanto na Prefeitura Municipal quanto na Câmara de Vereadores não é realizada nos padrões de acessibilidade com fontes ampliadas e escritas em braile, "[...] não existem materiais em braile ou panfletos com fontes ampliadas, o que deve ser revisto, isso não ocorre nem nas escolas, quem dirá na Prefeitura Municipal e na Câmara de Vereadores.”(G7).

Na Prefeitura Municipal de Santa Rosa, o painel disponível não está adaptado na parte sonora verbalizada, apenas emite sons de alerta, disponível apenas nos Caixas e na Fazenda Municipal. Na Câmara de Vereadores esse item é inexistente e a sua instalação se faz necessária para prover atendimento, principalmente, quando ocorre a concentração de um maior número de pessoas.

A categoria recursos está baseada nas subcategorias recursos financeiros e recursos humanos. A primeira categoria apresenta os recursos financeiros, os quais foram os mais abordados pelos gestores para provimento de acessibilidade. Assim, o município tem que prover contrapartida de forma autônoma, e isso, poucas vezes é possível, pois são muitas as demandas frente aos impostos municipais arrecadados.

O Prefeito está cortando verbas, a crise vem de uns dois anos para cá, sendo que no orçamento de 2017/2018 estão cortando recursos infelizmente, o governo não tem recursos suficientes para tudo, a gente acha que todo o político é ruim, mas eles não conseguem gerir com poucos recursos todas as demandas. (G3).

A segunda subcategoria são os recursos humanos envolvidos, que estão relacionados à capacitação de servidores e colaboradores bem como a contratação imediata de profissionais qualificados, tanto na Prefeitura Municipal quanto na Câmara de Vereadores, ou na maior divulgação do tema da acessibilidade. "Não se ouve falar em curso para comunicação 
básica de pessoas com deficiência, isso deveria ser previsto para os servidores municipais, ou então, a contratação de maior número de profissionais para atender os deficientes." (G5).

\section{Ações de Garantia à Acessibilidade}

As últimas cinco categorias relacionam-se com as ações para a garantia da acessibilidade na Prefeitura e na Câmara de Vereadores do município e foram denominas: prioridade de alocação de verbas públicas, reformas, legislação, omissão da necessidade de acessibilidade e barreiras de implantação.

A categoria prioridade de alocação de verbas públicas está baseada nas subcategorias políticas públicas de massa e políticas públicas de minorias.

A maioria das pessoas tende a ser individualista e apoiam causas de acessibilidade até o momento que ocorram divergências entre seus interesses e os investimentos a serem destinados para áreas divergentes das suas, e seus interesses sejam deixados de lado em função de investimentos em inovações de acessibilidade. (G1).

A segunda subcategoria é a política de prioridade de alocação de verbas públicas por meio de políticas públicas para minorias, alguns gestores públicos defendem que os órgãos e entidades representantes das pessoas com deficiência devem ter maior representatividade nos órgãos públicos para alocar mais ações a essa classe minoritária: "[...] as classes representantes das pessoas com deficiência, como a Associação de Pais e Amigos dos Deficientes (APADA), devem estar presentes em reuniões e decisões a serem tomadas, principalmente nas reformas e adequações dos espaços internos da Prefeitura.” (G5).

Os recursos arrecadados nos cofres públicos dificilmente são excedentes, e decisões de gestão se fazem necessárias para a sua melhor aplicabilidade. As funções do Estado são para toda a sociedade e, na maioria das vezes, não consegue atender todas as demandas, sendo necessárias estratégias para beneficiar o maior número de pessoas possível com os recursos existentes (CLEMENTE; CELESTINI, 2003).

A categoria reformas está baseada nas subcategorias estruturas antigas e estruturas novas. Referente a isso, o G11 salienta que:

O prédio da Prefeitura era um mercado antigamente, literalmente um galpão. As adequações neste ambiente são onerosas para promover a completa acessibilidade, sendo que existem outras prioridades antes, como a climatização para melhorar a qualidade do trabalho dos servidores, dentre outros. Quando se constrói um prédio novo, é muito mais simples implantar acessibilidade que em estruturas antigas como o prédio da Prefeitura. 
As reformas no prédio da Prefeitura Municipal estão apenas em fase inicial, como muitos gestores afirmaram, existem várias outras reformas competindo com a acessibilidade que também necessitam de recursos altos, como da execução de Projeto de Prevenção e Combate a Incêndio (PPCI) depois das recentes exigências do Corpo de Bombeiros, ou então, a climatização do prédio etc.

A segunda subcategoria são as edificações novas, as quais segundo os gestores já podem ser pensadas contemplando todos os requisitos exigidos na legislação atual como a acessibilidade de uma forma muito mais tranquila e de fácil execução. Na Câmara de Vereadores o processo em busca da acessibilidade está bem mais avançado em função de execuções recentes e construção de benfeitoria anexa nova: "Já na Câmara de Vereadores o processo foi diferente, foram cinco anos de reformas e construído um prédio anexo novo, atendendo às questões da acessibilidade, dando um passo frente ao prédio Palácio 14 de Julho." (G9).

A categoria legislação está baseada nas subcategorias obrigatoriedade recente, exigências altas e prazos de implantação. A primeira delas, obrigatoriedade recente da legislação de acessibilidade, tem sido abordada por muitos gestores como um assunto contemporâneo: "Acessibilidade é tema novo, antigamente era normal pegar um cadeirante no colo, por exemplo, para entrar em um ônibus, claro que isso está errado, mas as adaptações são feitas de forma gradativa.” (G8).

A segunda subcategoria, elevadas exigências da legislação de acessibilidade, foi abordada por alguns gestores públicos em razão dos elevados recursos humanos e financeiros envolvidos no processo da implantação da acessibilidade: "[...] existem muitos setores com baixo número de servidores, e as necessidades do município vão muito além da parte de acessibilidade, e contratar mais pessoas, exclusivamente, para esse fim é inviável atualmente." (G4).

No entanto, planos e cronogramas e ações deverão ser instituídos para implantar a acessibilidade de forma gradativa, acompanhando os recursos disponíveis. Do contrário, o Ministério Público realizará maiores cobranças e auditorias, pois os direitos da pessoa com deficiência estão resguardados legalmente.

A categoria omissão da necessidade de acessibilidade está baseada nas subcategorias acompanhantes de pessoa com deficiência e ausência de pessoa com deficiência nas benfeitorias. A falsa percepção de que não existe necessidade de se instaurar os espaços acessíveis tem dois fatores causais. De acordo com alguns gestores que relativizam o problema e fazem muitas pessoas pensarem que não existe a necessidade da acessibilidade.

A cultura de que a pessoa com deficiência é dependente está enraizada em nossa cultura brasileira, antigamente era comum ver 
pessoas carregando cadeirantes no colo e outros levando a cadeira de rodas ao lado, ou então, cegos com algum parente indo aos lugares, e essa concepção precisa mudar, muitas pessoas pensam que sempre terá alguém disponível para fazer as coisas para as pessoas com deficiência. (G10).

A segunda subcategoria é a ausência de pessoas com deficiência nos estabelecimentos. Os gestores afirmaram não perceber a presença de pessoas com deficiência na Prefeitura Municipal e na Câmara de Vereadores. "Esse público não vem quase nunca à Prefeitura Municipal e Câmara de Vereadores, é muito difícil encontrar uma pessoa com deficiência em nossos estabelecimentos." (G8).

A ausência de pessoas com deficiência na Prefeitura Municipal e na Câmara de Vereadores e a cooperação que os terceiros fornecem a este público estão sendo os fatores de causalidade relacionadas à baixa importância que, muitas vezes, se dá para o tema da acessibilidade. Por isso, a ausência desse público nos estabelecimentos da Prefeitura Municipal e da Câmara de Vereadores é um fator agravante que contribui para a inércia do avanço da acessibilidade.

A categoria barreiras de implantação está baseada nas subcategorias financeira, baixo número de pessoa com deficiência e baixa representatividade pessoa com deficiência. As barreiras para a implantação da acessibilidade e criação de políticas públicas foram associadas pelos gestores públicos, basicamente, em fatores que travam o processo de implantação das medidas de acessibilidade, e/ou responsáveis pela baixa motivação da gestão em alocar suas ações para a acessibilidade. A categoria financeira é a principal barreira na percepção dos gestores públicos: “[...] os maiores problemas para implantar a acessibilidade, principalmente nas edificações antigas que exigem reformas e gastos de retrabalho, são financeiros, pois o município tem que dar a total contrapartida com recursos, desconhecemos recursos da união para as Prefeituras.” (G1).

A segunda subcategoria é o baixo número de pessoas com deficiência. No entanto, esse número normalmente é maior que se pensa, afinal, muitas vezes, as pessoas com deficiência apenas passam despercebidos na sociedade. Quando questionados os gestores sobre a circulação das pessoas com deficiência na Prefeitura Municipal e na Câmara de Vereadores, muitos responderam que havia poucas frequentavam os estabelecimentos da Prefeitura Municipal e da Câmara de Vereadores: “[...] dificilmente vejo alguma pessoa com deficiência na Prefeitura ou na Câmara de Vereadores, as causas desconheço, talvez o número deles não seja tão alto, ou então, eles não frequentam nosso estabelecimento." (G2).

A terceira subcategoria é a baixa representatividade das pessoas com deficiência, uma vez que, os gestores afirmaram não perceber mão ativa das 
entidades e instituições representantes da classe: “[...] os órgãos associados às pessoas com deficiência devem tomar mais à frente e se envolver mais em políticas públicas para promoção da acessibilidade, afinal, eles são os seus representantes e têm o dever de lutar por melhorias." (G5).

\section{Conclusões}

Os órgãos públicos devem ofertar acessibilidade em suas benfeitorias como representantes legais do Estado. Nesse sentido, Santa Rosa/RS tomou a frente na previsão da acessibilidade por meio do novo Plano Diretor, de 2017 e pelo seu Código de Obras, de 2010. O município de Santa Rosa/ RS passa por um momento de adequação de sua legislação, uma vez que, já tinha um Plano Diretor vigente anteriormente, de 2006. Preocupada com as pessoas com deficiência e com seu planejamento urbano, Santa Rosa/ RS atualizou seu Plano Diretor a partir da legislação atual. A partir disso, surgiu a inquietação de analisar a acessibilidade na Prefeitura Municipal e na Câmara de Vereadores do respectivo município, sob a percepção dos seus gestores públicos.

$\mathrm{Na}$ percepção dos gestores, a Câmara de Vereadores se mostrou muito mais acessível que o prédio da Prefeitura Municipal, trazendo uma taxa de acessibilidade de 46,61\% para itens acessíveis e 53,39\% para itens não acessíveis de todos os itens investigados, pois metade destes estava nos padrões de acessibilidade. O prédio da Prefeitura Municipal, por sua vez, teve um percentual de itens acessíveis bem inferiores à Câmara de Vereadores, chegando a apenas 33,07\% de itens acessíveis e 66,93\% não acessíveis. A Câmara de Vereadores se tornou mais acessível que a Prefeitura Municipal na percepção dos gestores públicos por causa das reformas e da parte nova edificada conforme constatado na etapa qualitativa da pesquisa. Em complemento, por possuir mais itens visualmente perceptíveis, como a presença de elevador, sanitários e corrimão na rampa de acesso principal.

Em adição, a maioria dos gestores públicos percebeu de forma pouco significativa, a presença de pessoas com deficiência na Prefeitura Municipal e na Câmara de Vereadores, bem como as entidades representantes dessa classe se fazem pouco presentes nas decisões de gestão. A acessibilidade é um tema recente na percepção da maioria dos gestores públicos entrevistados, embora a legislação seja mais antiga. $\mathrm{O}$ desconhecimento de todas as exigências de acessibilidade previstas em norma e na legislação foram um dos principais limitadores da pesquisa, pois muitos sabiam apenas do básico que ouviram falar de outras pessoas a respeito da acessibilidade. A baixa presença de pessoas com deficiência na Prefeitura Municipal e na Câmara de Vereadores também foi um limitador da pesquisa, pois foram poucos gestores que presenciaram vivências concretas de dificuldades das pessoas 
com deficiência na prática, uma vez que, todos fazem seus julgamentos e percepções com base nas suas rotinas diárias.

\section{Referências}

ASSOCIAÇÃO BRASILEIRA DE NORMAS TÉCNICAS (ABNT). NBR 15599/2008: acessibilidade: comunicação na prestação de serviços. Rio de Janeiro: ABNT, 2008.

ASSOCIAÇÃO BRASILEIRA DE NORMAS TÉCNICAS (ABNT). NBR 9050/2015: acessibilidade a edificações, mobiliário, espaços e equipamentos urbanos. Rio de Janeiro: ABNT, 2015.

BARDIN, L. Análise de conteúdo. Lisboa: Edições 70, 2006.

BOLONHINI JUNIOR, R. Portador de necessidades especiais: as principais prerrogativas dos Portadores de Necessidades Especiais e a Legislação Brasileira. 2. ed. São Paulo: Atlas, 2010.

CLEMENTE, C. A.; CELESTINI, E. C. Trabalhando com a diferença: responsabilidade social e inclusão de Portadores de Deficiência. Espaço da Cidadania. Osasco: Gráfica e Editora Peres, 2003.

CRUZ, D. A. M. O. As faces do planejamento. Revista Pegada, São Pulo, v. 12, n. 2, p. 1-14, 2011.

INSTITUTO BRASILEIRO DE GEOGRAFIA E ESTATISTICA (IBGE). Rio Grande do Sul. 2013. Disponível em: http://cidades.ibge.gov.br/download/ mapa_e_municipios.php?lang=\&uf=rs. Acesso em: 18 out. 2018.

INSTITUTO BRASILEIRO DE GEOGRAFIA E ESTATISTICA (IBGE). Perfil dos Municípios Brasileiros 2011: tabelas (em formato xls compactado). Portal virtual. 2011. Disponível em: http://www.ibge.gov.br/home/estatistica/ economia/perfilmunic/2011/defaulttabzip_xls.shtm. Acesso em: 18 out. 2018.

INSTITUTO BRASILEIRO DE GEOGRAFIA E ESTATISTICA (IGBE). Pesquisa Nacional de Saúde (PNS) 2013: percepção do estado de saúde, estilos de vida e doenças crônicas - Brasil, grandes regiões e Unidades da Federação. Rio de Janeiro, 2014. Disponível em: ftp://ftp.ibge.gov.br/PNS/2013/pns2013.pdf. Acesso em: 18 out. 2018.

LAMÔNICA, D. A. C.; ARAÚJO FILHO, P.; SIMOMELLI, S. B. J. Acessibilidade em ambiente universitário: identificação de barreiras arquitetônicas no campus da USP de Bauru. Revista Brasileira de Educação Especial, São Paulo, v. 14, n. 2 , p. $177-188,2008$.

LIMA, L. H. Acessibilidade para pessoas portadoras de deficiências: requisito da legalidade, legitimidade e economicidade das edificações públicas. Revista do TCU, Brasília, DF, v. 41, p. 72-78, nov. 2006. Disponível em: http://revista.tcu.gov. br/ojs/index.php/RTCU/article/view/293/338. Acesso em: 18 out. 2018.

ORGANIZAÇÃO DAS NAÇÕES UNIDAS (ONU). A ONU e as Pessoas com Deficiência. 2016. Disponível em: https://nacoesunidas.org/acao/pessoascom-deficiencia/. Acesso em: 05 jun. 2016. 
PASTORE, J. Oportunidade de trabalho para portadores de deficiência. São Paulo: LTr Editora, 2000.

SANTA ROSA/RS. Lei Complementar Municipal n. 58, de 12 de abril de 2010. Institui o Código de Obras do município de Santa Rosa. 2010. Disponível em: https://www.camarasantarosa.rs.gov.br/camara/proposicao/LeiComplementar/2010/1/0/0. Acesso em: 17 out. 2019.

SANTA ROSA/RS. Lei Complementar Municipal n. 118, de 28 de agosto de 2017. Plano Diretor Participativo de Desenvolvimento Sustentável do Município de Santa Rosa. 2017. Disponível em: https://www.camarasantarosa.rs.gov.br/ camara/proposicao/Lei-Complementar/2017/1/0/0. Acesso em: 17 out. 2019.

SANTA ROSA/RS.Lei ComplementarMunicipaln.33,de11 de outubrode2006. Institui o Plano Diretor Participativo de Desenvolvimento Municipal Sustentável de Santa Rosa e dá outras providências. 2006. Disponível em: https://www. camarasantarosa.rs.gov.br/camara/proposicao/Lei-Complementar/2006/1/0/0. Acesso em: 17 out. 2019.

SASSAKI, R. K. Terminologia sobre deficiência na era da inclusão. Revista Nacional de Reabilitação, São Paulo, v. 5, n. 25, p. 5-14, mar./abr. 2002.

SASSAKI, R. K. Inclusão: acessibilidade no lazer, trabalho e educação. Revista Nacional de Reabilitação, São Paulo, Ano XII, p. 10-16, mar./abr. 2009.

SECRETARIA NACIONAL DE TRANSPORTE E MOBILIDADE URBANA (SEMOB). Ministério das Cidades. Programa Brasileiro de Acessibilidade Urbana. 2015. Disponível em: http://www.secid.ma.gov.br/ files/2015/03/BrasilAcessivelCaderno04.pdf. Acesso em: 18 out. 2018.

TAVARES FILHO, J. P. et al. Aspectos ergonômicos da interação com caixas automáticos bancários de usuários com necessidades especiais características de idosos. In: CONGRESSO IBEROLATINOAMERICANO DE INFORMÁTICA EDUCATIVA ESPECIAL, 3., 2002, Fortaleza. Anais [...] Fortaleza: [s.n.], 2002.

TRIBUNAL DE CONTAS DA UNIÃO (TCU). 2012. Relatório de Auditoria Operacional: acessibilidade nos Órgãos Públicos Federais. Brasília, DF, 2012. Disponível em: http://portal.tcu.gov.br/lumis/portal/file/fileDownload.jsp?inline =1\&fileId=8A8182A14D92792C014D92835C2569F3. Acesso em: 18 out. 2018.

Recebido: 05/08/2019

Aceito: 09/10/2019 


\title{
ACCESSIBILITY OFFER IN THE CITY HALL AND IN THE CITY COUNCIL OFTHE MUNICIPALITY OF SANTA ROSA/RS
}

\begin{abstract}
Considering the importance of urban accessibility in promoting the quality of life and the legitimation of the citizenship exercise for people with disabilities, this paper analyzes the offer of accessibility in 2017 in the City Hall and the City Council of the municipality of Santa Rosa/RS. The qualitative study was carried out through documentary analysis, interviews, and direct observation. The documentary analysis covered federal standards and municipal legislation. Through the interviews, the perception of 12 municipal public managers was verified. There was also a structured observation of accessibility criteria. The results indicate that the city of Santa Rosa has proved to be one of the forerunners about the legislation that serves disabled person. In the manager's perception, the structure of the City Council was more accessible than the building of the City Hall. Conclusively, it can be seen that the presence of disabled person is insignificant in the municipal public spaces investigated, preventing concrete experiences and awareness of the limitations of these municipalities when attending them.
\end{abstract}

Keywords: Municipal Managers. People with Disabilities. Interviews.

\section{OFERTA DE ACCESIBILIDAD EN EL AYUNTAMIENTO MUNICIPAL Y EN LA CÁMARA DE CONCEJALES DEL MUNICIPIO DE SANTA ROSA/RS}

\begin{abstract}
Resumén
En vista de la importancia de la accesibilidad urbana en la promoción de la calidad de vida y legitimación del ejercicio de la ciudadanía a personas con discapacidad, en este trabajo se analiza su oferta, en el año 2017, en el Ayuntamiento Municipal y en la Cámara de Concejales del municipio de Santa Rosa/RS. El estudio de abordaje cualitativo fue realizado por medio de análisis documental, entrevistas, y observación directa. El análisis documental abarcó las normas federales y la legislación municipal. Por medio de las entrevistas, se verificó la percepción de 12 gestores públicos municipales. También se realizó una observación estructurada de los criterios de accesibilidad. Los resultados apuntan que el municipio se ha mostrado uno de los precursores en lo que se refiere a la legislación que atiende a persona discapacitada. En la percepción de los gestores, la estructura de la Cámara se mostró más accesible que el edificio del Ayuntamiento Municipal. Conclusivamente, se percibe que la presencia de persona discapacitada es poco significativa en los espacios públicos municipales investigados, impidiendo vivencias concretas y conciencias de las limitaciones de esos ciudadanos al frecuentarlos.
\end{abstract}

Palabras clave: Gestores Municipales. Personas con Discapacidad. Entrevistas. 